\title{
Establishing Baseline Cervical Cancer Screening Coverage — India, 2015-2016
}

\author{
Elizabeth A. Van Dyne, MD ${ }^{1,2}$; Benjamin D. Hallowell, $\mathrm{PhD}^{2}$; Mona Saraiya, MD²; Virginia Senkomago, PhD 2 ; Shivani A. Patel, PhD³; \\ Sutapa Agrawal, $\mathrm{PhD}^{4}$; Arpita Ghosh, $\mathrm{PhD}^{4}$; Deepika Saraf, $\mathrm{PhD}^{5}$; Ravi Mehrotra, MD ${ }^{5}$; Preet K. Dhillon, $\mathrm{PhD}^{4}$
}

Cervical cancer is the second leading cause of new cancer cases and cancer-related deaths among women in India, with an estimated 96,922 new cases and 60,078 deaths each year.* Despite the availability of effective low-cost screening options in India, limited access to screening and treatment services, diagnosis at a later stage, and low investment in health care infrastructure all contribute to the high number of deaths (1). In 2016 the Ministry of Health and Family Welfare of India recommended cervical cancer screening using visual inspection with acetic acid every 5 years for women aged 30-65 years (per World Health Organization [WHO] guidelines) $(2,3)$. To establish a baseline for cervical cancer screening coverage, survey data were analyzed to estimate the percentage of women aged 30-49 years who had ever been screened for cervical cancer (defined as ever having had a cervix examination). Cervical cancer screening was estimated using data from the Fourth National Family Health Survey ${ }^{\dagger}$ (NFHS-4), a nationally representative survey conducted at the district level during 2015-2016, which included 699,686 Indian women aged 15-49 years. Lifetime cervical cancer screening prevalence was low $(29.8 \%)$ and varied by geographic region, ranging from $10.0 \%$ in the Northeast Region to $45.2 \%$ in the Western Region. Prevalence of screening was higher among women with higher levels of education and household wealth, those who had ever been married, and urban residents. This screening prevalence can be used as a baseline indicator for cervical cancer screening in India in accordance with the WHO Noncommunicable Diseases Global Monitoring Framework during state-based programmatic rollout and program evaluation (4).

The 2015-2016 NFHS-4, a cross-sectional, nationally representative survey, was conducted in all 29 states and seven union territories in India; it included a sample of 699,686 women aged 15-49 years in both urban and rural areas, with a $97.6 \%$ response rate. The survey questionnaire underwent pretesting and was translated into 18 regional languages and back-translated to ensure consistency. To ascertain cervical cancer screening, women aged 30-49 years were asked "Have you ever undergone a cervix examination?" Weighted prevalence estimates of women who reported screening and

\footnotetext{
*International Agency for Research on Cancer Global Cancer Observatory. http://gco.iarc.fr/today/data/factsheets/populations/356-india-fact-sheets.pdf.

$\dagger$ National Family Health Survey-4, India, 2015-2016, data version 73. http:// rchiips.org/NFHS/nfhs4.shtml and https://dhsprogram.com/.
}

95\% confidence intervals (CIs) were calculated. Chi-squared tests were used to assess statistical significance of differences, defined as a p-value $<0.05$. Data were stratified by age, rural/ urban residence, level of education, marital status, household wealth index, ${ }^{\S}$ religion, work status, caste/tribe status, ${ }^{\mathbb{S}}$ partner's education, and geographic region. ${ }^{* *}$ Maps were created to display weighted prevalence estimates.

Overall, among 336,777 women aged 30-49 years, $29.8 \%$ $(95 \% \mathrm{CI}=29.4 \%-30.2 \%)$ reported ever having been screened for cervical cancer (Table). Screening prevalence increased with women's educational level and that of their partners, ranging from $24.7 \%$ among women with no formal education to $37.1 \%$ among women who had completed grade 12 or higher, and from $26.3 \%$ among those whose partners had no formal education to $36.9 \%$ among those whose partners had at least a grade 12 level education.

Cervical cancer screening prevalence varied by women's marital status, from a low of $6.2 \%$ among those who were never married to $30.5 \%$ among those who were currently married. When assessed by household wealth, prevalence was lowest among women from the poorest households (17.1\%) and highest among those from the wealthiest households (40.4\%). Screening prevalences were lower among Hindu (29.4\%) and Muslim (26.8\%) women than among Sikh (50.2\%), Buddhist (48.2\%), and Christian (39.1\%) women,

\footnotetext{
$\$$ The household wealth index is a composite measure of a household's cumulative living standard. The wealth index is calculated using data on a household's ownership of selected assets, such as televisions and bicycles, materials used for housing construction, and types of water access and sanitation facilities.

I Scheduled Classes, Scheduled Tribes, and "Other Backward Classes" are constitutionally recognized categories describing historically, socially, educationally, and/or economically disadvantaged groups that are officially recognized in India. "General" is a group that has a higher status in the caste hierarchy. Scheduled Castes are castes that the Government of India identifies as in need of special protection from social injustice and exploitation. They are explicitly recognized by the Constitution of India, were previously called the "depressed classes" by the British; other past names were untouchables or dalits. Scheduled Tribes consist of approximately 700 tribes that tend to be geographically isolated and have limited economic and social interaction with the rest of the population. Although there is a substantial degree of heterogeneity within each category, these categories are routinely used for population-based monitoring in India.

** North: Haryana, Himachal Pradesh, Jammu and Kashmir, Punjab, and Rajasthan. Central: Chhattisgarh, Madhya Pradesh, Uttarakhand, and Uttar Pradesh. East: Bihar, Jharkhand, Odisha, and West Bengal. Northeast: Arunachal Pradesh, Assam, Manipur, Meghalaya, Mizoram, Nagaland, Sikkim, and Tripura. Western: Goa, Gujarat, and Maharashtra. South: Andhra Pradesh, Karnataka, Kerala, Tamil Nadu, and Telangana. Union territories: Andaman and Nicobar Islands, Chandigarh, Dadra and Nagar Haveli, Daman and Diu, Delhi, Lakshadweep, and Puducherry.
} 
TABLE. Prevalence of cervical cancer screening among women aged 30-49 years, by demographic and socioeconomic characteristics — Fourth National Family Health Survey, India, 2015-2016

\begin{tabular}{|c|c|c|c|}
\hline Characteristic & No. in sample & Weighted screening prevalence, $\%$ (95\% Cl) & p-value (chi-squared)* \\
\hline Overall & 336,777 & $29.8(29.4-30.2)$ & - \\
\hline \multicolumn{4}{|l|}{ Age group (yrs) } \\
\hline $30-34$ & 97,048 & $29.0(28.4-29.6)$ & $<0.0001$ \\
\hline $35-39$ & 90,433 & $29.5(29.0-30.0)$ & \\
\hline $40-44$ & 76,627 & $30.4(29.9-31.0)$ & \\
\hline $45-49$ & 72,669 & $30.7(30.1-31.3)$ & \\
\hline \multicolumn{4}{|l|}{ Education } \\
\hline No education & 143,607 & $24.7(24.2-25.2)$ & $<0.0001$ \\
\hline Grades 1-8 & 96,582 & $29.9(29.4-30.4)$ & \\
\hline Grades 9-11 & 51,753 & $36.9(36.1-37.8)$ & \\
\hline Grades $\geq 12$ & 44,835 & $37.1(36.1-38.1)$ & \\
\hline \multicolumn{4}{|l|}{ Partners' education ${ }^{\dagger}$} \\
\hline No education & 13,470 & $26.3(25.1-27.5)$ & $<0.0001$ \\
\hline Grades 1-8 & 18,214 & $31.4(30.3-32.6)$ & \\
\hline Grades 9-11 & 13,735 & $35.9(34.4-37.3)$ & \\
\hline Grades $\geq 12$ & 12,524 & $36.9(35.2-38.5)$ & \\
\hline \multicolumn{4}{|l|}{ Marital status } \\
\hline Never married & 7,165 & $6.2(5.0-7.3)$ & $<0.0001$ \\
\hline Currently married & 305,662 & $30.5(30.1-30.9)$ & \\
\hline Widowed & 18,838 & $25.9(24.9-27.0)$ & \\
\hline Divorced/Separated/Deserted & 5,112 & $24.9(23.0-26.9)$ & \\
\hline \multicolumn{4}{|l|}{ No. of children } \\
\hline 0 & 17,562 & $27.6(26.4-28.8)$ & $<0.0001$ \\
\hline 1 & 31,029 & $33.0(32.0-34.0)$ & \\
\hline 2 & 98,185 & $34.0(33.4-34.6)$ & \\
\hline$\geq 3$ & 190,001 & $26.8(26.5-27.2)$ & \\
\hline \multicolumn{4}{|l|}{ Household wealth index ${ }^{\S}$} \\
\hline Poorest & 63,723 & $17.1(16.6-17.5)$ & $<0.0001$ \\
\hline Poor & 69,441 & $23.1(22.5-23.6)$ & \\
\hline Middle & 68,525 & $30.2(29.5-30.8)$ & \\
\hline Rich & 67,191 & $34.7(33.9-35.4)$ & \\
\hline Richest & 67,897 & $40.4(39.5-41.3)$ & \\
\hline \multicolumn{4}{|l|}{ Working status $^{\dagger}$} \\
\hline Currently working & 17,732 & $31.9(30.7-33.1)$ & 0.6000 \\
\hline Not currently working & 41,489 & $32.1(31.3-33.0)$ & \\
\hline \multicolumn{4}{|l|}{ Religion ${ }^{\pi}$} \\
\hline Hindu & 252,410 & $29.4(29.0-29.9)$ & $<0.0001$ \\
\hline Muslim & 40,686 & $26.8(25.9-27.8)$ & \\
\hline Christian & 26,378 & $39.1(37.0-41.1)$ & \\
\hline Sikh & 7,953 & $50.2(47.3-53.0)$ & \\
\hline Buddhist & 4,587 & $48.2(43.4-52.9)$ & \\
\hline Jain & 597 & $38.6(32.3-44.8)$ & \\
\hline Other & 4,166 & $9.1(7.3-11.0)$ & \\
\hline \multicolumn{4}{|l|}{ Caste/Tribe status** } \\
\hline Scheduled Caste & 57,860 & $28.2(27.3-29.1)$ & $<0.0001$ \\
\hline Scheduled Tribe & 61,013 & $25.1(24.2-26.1)$ & \\
\hline "Other Backward Class" & 130,332 & $30.8(30.3-31.4)$ & \\
\hline General & 85,963 & $31.2(30.5-31.9)$ & \\
\hline Do not know & 1,609 & $17.3(14.4-20.2)$ & \\
\hline \multicolumn{4}{|l|}{ Place of residence } \\
\hline Urban & 102,300 & $34.0(33.2-34.8)$ & $<0.0001$ \\
\hline Rural & 234,477 & $27.5(27.1-27.9)$ & \\
\hline \multicolumn{4}{|l|}{ Geographic regions ${ }^{t \dagger}$} \\
\hline North & 56,018 & $37.0(36.2-37.9)$ & $<0.0001$ \\
\hline Central & 91,087 & $22.7(22.1-23.3)$ & \\
\hline East & 59,048 & $15.7(15.2-16.2)$ & \\
\hline Northeast & 49,292 & $10.0(9.5-10.5)$ & \\
\hline Western & 27,537 & $45.2(43.8-46.6)$ & \\
\hline South & 45,070 & $38.1(37.2-39.0)$ & \\
\hline Union Territories & 8,725 & $41.2(35.3-47.0)$ & \\
\hline
\end{tabular}

See table footnotes on next page. 
TABLE. (Continued) Prevalence of cervical cancer screening among women aged 30-49 years, by demographic and socioeconomic characteristics Fourth National Family Health Survey, India, 2015-2016

\begin{tabular}{|c|c|c|c|}
\hline Characteristic & No. in sample & Weighted screening prevalence, $\%$ (95\% Cl) & p-value (chi-squared)* \\
\hline \multicolumn{4}{|l|}{ State/Union territory by region } \\
\hline North & & & $<0.0001$ \\
\hline Haryana & 10,097 & $42.0(39.8-44.1)$ & \\
\hline Himachal Pradesh & 5,604 & $30.8(28.5-33.0)$ & \\
\hline Jammu and Kashmir & 11,107 & $50.7(48.7-52.8)$ & \\
\hline Punjab & 10,210 & $51.3(48.3-54.2)$ & \\
\hline Rajasthan & 19,000 & $26.0(24.7-27.3)$ & \\
\hline \multicolumn{4}{|l|}{ Central } \\
\hline Chhattisgarh & 11,551 & $23.7(21.9-25.4)$ & \\
\hline Madhya Pradesh & 29,475 & $30.1(29.0-31.1)$ & \\
\hline Uttarakhand & 8,103 & $23.0(21.2-24.8)$ & \\
\hline Uttar Pradesh & 41,958 & $19.2(18.4-19.9)$ & \\
\hline \multicolumn{4}{|l|}{ East } \\
\hline Bihar & 20,215 & $18.1(17.2-19.0)$ & \\
\hline Jharkhand & 13,282 & $15.3(14.3-16.4)$ & \\
\hline Odisha & 16,837 & $34.4(32.8-36.0)$ & \\
\hline West Bengal & 8,714 & $5.2(4.6-5.9)$ & \\
\hline \multicolumn{4}{|l|}{ Northeast } \\
\hline Arunachal Pradesh & 7,291 & $10.5(9.3-11.6)$ & \\
\hline Assam & 13,942 & $6.3(5.6-7.0)$ & \\
\hline Manipur & 7,156 & $25.5(24.1-27.0)$ & \\
\hline Meghalaya & 4,087 & $27.0(24.6-29.5)$ & \\
\hline Mizoram & 6,314 & $30.9(28.6-33.2)$ & \\
\hline Nagaland & 5,518 & $20.9(19.3-22.5)$ & \\
\hline Sikkim & 2,559 & $15.9(13.7-18.2)$ & \\
\hline Tripura & 2,425 & $7.6(6.0-9.2)$ & \\
\hline \multicolumn{4}{|l|}{ Western } \\
\hline Goa & 989 & $64.6(59.3-69.8)$ & \\
\hline Gujarat & 11,788 & $33.2(31.2-35.2)$ & \\
\hline Maharashtra & 14,760 & $51.0(49.2-52.8)$ & \\
\hline \multicolumn{4}{|l|}{ South } \\
\hline Andhra Pradesh & 5,618 & $42.6(40.4-44.8)$ & \\
\hline Karnataka & 13,567 & $18.4(16.9-20.0)$ & \\
\hline Kerala & 6,399 & $78.1(76.3-80.0)$ & \\
\hline Tamil Nadu & 15,724 & $31.0(29.7-32.4)$ & \\
\hline Telangana & 3,762 & $41.2(38.2-44.3)$ & \\
\hline \multicolumn{4}{|l|}{ Union territories } \\
\hline Andaman and Nicobar Islands & 1,563 & $28.8(23.4-34.3)$ & \\
\hline Chandigarh & 385 & $73.6(66.1-81.0)$ & \\
\hline Dadra and Nagar Haveli & 361 & $23.4(16.8-30.1)$ & \\
\hline Daman and Diu & 677 & $52.6(44.3-60.9)$ & \\
\hline Delhi & 2,899 & $40.7(33.7-47.8)$ & \\
\hline Lakshadweep & 596 & $71.8(66.7-76.8)$ & \\
\hline Puducherry & 2,244 & $28.9(22.2-35.6)$ & \\
\hline
\end{tabular}

* Chi-square test, significantly different if $p<0.05$ among groups; $p$-values were calculated using prevalence to the hundredth decimal place.

† Partners' education and work status were collected in only a random subset of households selected for state-modules and limited to married women so do not sum to total.

$\S$ The household wealth index is a composite measure of a household's cumulative living standard. The wealth index is calculated using data on a household's ownership of selected assets such as televisions and bicycles, materials used for housing construction, and types of water access and sanitation facilities.

" Other included Jewish, Parsi/Zoroastrian, no religion, and other religion.

** Scheduled Caste, Scheduled Tribe, and "Other Backward Class" are constitutionally recognized categories describing historically, socially, educationally, and/or economically disadvantaged groups that are officially recognized in India. "General" is a category that does not belong to any of the prior three categories. Although there is a substantial degree of heterogeneity within each category, these categories are routinely used for population-based monitoring in India.

t+ North: Haryana, Himachal Pradesh, Jammu and Kashmir, Punjab, and Rajasthan. Central: Chhattisgarh, Madhya Pradesh, Uttarakhand, and Uttar Pradesh. East: Bihar, Jharkhand, Odisha, and West Bengal. Northeast: Arunachal Pradesh, Assam, Manipur, Meghalaya, Mizoram, Nagaland, Sikkim, and Tripura. Western: Goa, Gujarat, and Maharashtra. South: Andhra Pradesh, Karnataka, Kerala, Tamil Nadu, and Telangana. Union territories: Andaman and Nicobar Islands, Chandigarh, Dadra and Nagar Haveli, Daman and Diu, Delhi, Lakshadweep, and Puducherry. 
and lower among women who belonged to a Scheduled Tribe $(25.1 \%)$ or Scheduled Caste $(28.2 \%)$ than among women in "Other Backward Classes" (30.8\%) or the general category.

Geographically, screening prevalence was higher among women in urban $(34.0 \%)$ than among those in rural $(27.5 \%)$ areas, and higher in the Western Region (45.2\%), union territories (41.2\%), South Region (38.1\%), and North Region (37.0\%) than in the Northeast (10.0\%), East (15.7\%), and Central $(22.7 \%)$ regions (Figure). Across states, screening prevalence ranged from 5.2\% (West Bengal) to 78.1\% (Kerala) (Table).

\section{Discussion}

Nationally, fewer than one in three Indian women reported having been screened for cervical cancer, although screening prevalence was highly variable across states and within districts, and was higher in urban areas. Higher screening prevalence was associated with education of women and their partners, wealth, and marriage.

The operational framework in India recommends a screen-andtreat approach using visual inspection with acetic acid, consistent with WHO guidelines for countries that do not have cervical cancer screening programs in place or resources for Papanicolaou (Pap) or human papillomavirus testing ${ }^{\dagger \dagger}(2,3)$. Visual inspection with acetic acid screening programs in India have been found through randomized controlled trials to effectively reduce cervical cancer mortality by approximately $30 \%(5,6)$.

The historical focus of the health system in India has been on maternal and child health and communicable diseases. However, it is also important to take into account the epidemiologic transition and demographic shift in the Indian population to more disability-adjusted life years from noncommunicable, chronic diseases than from communicable, maternal, neonatal, and nutritional diseases (7). The decision of India's Ministry of Health and Family Welfare to provide guidance in 2016 on universal population-based cervical cancer screening among women aged 30-65 years is a response to this epidemiologic transition. Screening of women in the target population will be recommended every 5 years; surveillance during the initial rollout and each 5-year interval will be evaluated, and strategies will be modified to improve screening rates (2).

The national and state cervical cancer screening baseline estimates in this study can be used for programmatic rollout, implementation benchmarks, and program evaluation in accordance with the $\mathrm{WHO}$ cervical cancer indicator ${ }^{\mathbb{\$}}$ for women

\footnotetext{
$\dagger^{\dagger}$ http://nicpr.res.in/images/PDF/guidelines_for_population_level_screening of_common_NCDs.pdf.

$\$ \$$ Proportion of women aged $30-49$ years screened for cervical cancer at least once, or more often, and for lower or higher age groups according to national programs or policies.
}

aged 30-49 years screened for cervical cancer (4). Cervical cancer screening can also be monitored in age groups outside the recommended guidelines to evaluate effective implementation of screening recommendations.

The findings of this study are subject to at least three limitations. First, despite the intention that the survey question serve as an indicator for cervical cancer screening, women might have reported cervical examinations that were not related to cervical cancer screening. This could lead to an overestimation of screening prevalence. There is a concern that women might have confused a pelvic exam with a cervical cancer screening test; however, as in the United States, self-reported questions have proved to be a consistent way of measuring screening prevalence in countries with no organized screening program or screening registries $(8,9)$. Second, it is possible that women might have responded in a manner they viewed as more socially acceptable. Finally, with dialect differences, survey questions might not have been fully understood. The next version of the survey (NFHS-5) will specifically ask women whether they have undergone a screening test for cervical cancer. A study to determine accuracy of self-reported screening of the survey question compared with that of clinical records might be beneficial.

The main strength of this study is the large sample size of the nationally representative survey. These are the first reported data on cervical cancer screening in India that allow examination across all states and union territories down to the district level. Previous national estimates were based on smaller sample sizes in older data sources; for example, the 2003 World Health Survey, a household survey of 3,954 women found that 5.3\% of Indian women aged 25-64 years reported having been screened with a Pap test in the past 3 years (10).

Moving forward with the state-level screening program rollouts in India, it is important to consider how socioeconomic factors might be associated with acceptance of screening at the district, state, and national levels. In the future, these baseline data can be used to plan and evaluate cervical cancer screening programs, perform cost-effectiveness analyses, and evaluate facility readiness. Prioritizing geographic areas and groups with lower screening prevalences might be needed to progress to India's national goal of universal cervical cancer screening (3). 99

At the May 2018 World Health Assembly, the WHO Director-General issued a call to action to eliminate cervical cancer globally as a public health problem, including comprehensive strategies such as vaccination, screening, and treatment. ${ }^{* * *}$ Strong surveillance systems that include cancer

\footnotetext{
99 https://www.bmj.com/content/bmj/355/bmj.i5574.full.pdf.

*** https://www.who.int/reproductivehealth/call-to-action-elimination-cervicalcancer/en.
} 
FIGURE. Prevalence of cervical cancer screening among women aged 30-49 years, by district — National Family Health Survey-4, India, 2015-2016

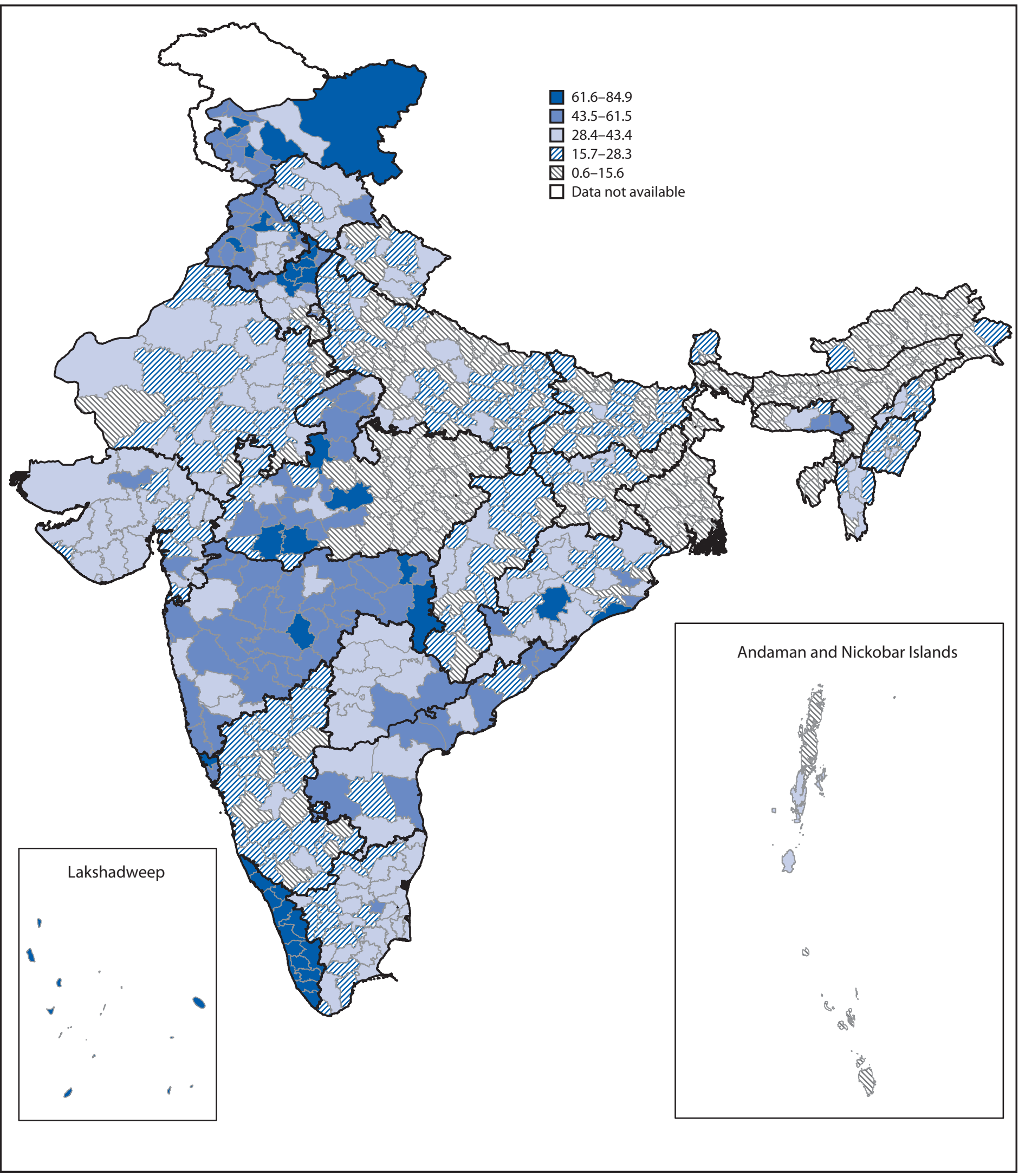




\section{Summary}

What is already known about this topic?

Cervical cancer is the second leading cause of cancer mortality among women in India; in 2016 the Ministry of Health and Family Welfare of India recommended population-based cervical cancer screening in women aged $\geq 30$ years.

What is added by this report?

Among women in India aged 30-49 years, less than one third (29.8\%) reported ever having been screened for cervical cancer. There was substantial geographic variation, and screening prevalence was associated with education of women and their partners, wealth, and marriage.

What are the implications for public health practice?

These estimates can be used as baseline data to plan cervical cancer screening targeted interventions, programmatic rollouts, and evaluation to help India meet the goal of universal cervical cancer screening.

registries, national surveys, or registries that can measure screening or vaccination coupled with modeling will all play an important role in ensuring that cervical cancer can be eliminated as a public health problem in women.

\footnotetext{
${ }^{1}$ Epidemic Intelligence Service, CDC; ${ }^{2}$ Division of Cancer Prevention and Control, National Center for Chronic Disease Prevention and Health Promotion, CDC; ${ }^{3}$ Emory University, Atlanta, Georgia; ${ }^{4}$ Public Health Foundation of India, New Delhi, India; ${ }^{5}$ National Institute for Cancer Prevention and Research, Noida, India.

Corresponding author: Mona Saraiya, msaraiya@cdc.gov, 770-488-4293.

All authors have completed and submitted the ICMJE form for disclosure of potential conflicts of interest. No potential conflicts of interest were disclosed.
}

\section{References}

1. Ginsburg O, Bray F, Coleman MP, et al. The global burden of women's cancers: a grand challenge in global health. Lancet 2017;389:847-60. https://doi.org/10.1016/S0140-6736(16)31392-7

2. World Health Organization. WHO guidelines for screening and treatment of precancerous lesions for cervical cancer prevention. Geneva, Switzerland: World Health Organization; 2013. https://apps.who.int/ iris/bitstream/10665/94830/1/9789241548694_eng.pdf

3. Government of India Ministry of Health and Family Welfare. Operational framework: management of common cancers. New Delhi, India: Government of India Ministry of Health and Family Welfare; 2016. http://cancerindia.org.in/wp-content/uploads/2017/11/ Operational_Framework_Management_of_Common_Cancers.pdf

4. World Health Organization. 25 indicators of noncommunicable diseases global monitoring framework. Geneva, Switzerland: World Health Organization; 2014. https://www.who.int/nmh/global_monitoring_framework/2013-1106-who-dc-c268-whp-gap-ncds-techdoc-def3.pdf?ua=1

5. Shastri SS, Mittra I, Mishra GA, et al. Effect of VIA screening by primary health workers: randomized controlled study in Mumbai, India. J Natl Cancer Inst 2014;106:dju009. https://doi.org/10.1093/jnci/dju009

6. Sankaranarayanan R, Esmy PO, Rajkumar R, et al. Effect of visual screening on cervical cancer incidence and mortality in Tamil Nadu, India: a cluster-randomised trial. Lancet 2007;370:398-406. https:// doi.org/10.1016/S0140-6736(07)61195-7

7. India State-Level Disease Burden Initiative Collaborators. Nations within a nation: variations in epidemiological transition across the states of India, 1990-2016 in the Global Burden of Disease Study. Lancet 2017;390:2437-60. https://doi.org/10.1016/S0140-6736(17)32804-0

8. Rauscher GH, Johnson TP, Cho YI, Walk JA. Accuracy of selfreported cancer-screening histories: a meta-analysis. Cancer Epidemiol Biomarkers Prev 2008;17:748-57. https://doi.org/10.1158/1055-9965. EPI-07-2629

9. Viens L, Perin D, Senkomago V, Neri A, Saraiya M. Questions about cervical and breast cancer screening knowledge, practice, and outcomes: a review of demographic and health surveys. J Womens Health (Larchmt) 2017;26:403-12. https://doi.org/10.1089/jwh.2017.6441

10. Gakidou E, Nordhagen S, Obermeyer Z. Coverage of cervical cancer screening in 57 countries: low average levels and large inequalities. PLoS Med 2008;5:e132. https://doi.org/10.1371/journal.pmed.0050132 